\title{
INFLUÊNCIA GERMÂNICA NOS PRIMÓRDIOS DA ENFERMAGEM PROFISSIONAL NA CIDADE DO RECIFE, PERNAMBUCO (1924-1927)
}

\author{
Germanic influence in the early days of professional nursing in \\ the city of Recife, Pernambuco (1924-1927)

\section{Influencia germánica en los inicios de la enfermería profesional en la ciudad de recife, pernambuco (1924-1927)}

Fátima Maria da Silva Abrão ${ }^{1}$
Niellys de Fátima da Conceição Gonçalves Costa ${ }^{4}$
Regina Célia de Oliveira²

Vanessa Maria de Brito Sales ${ }^{5}$
Natally da Silva Freitas ${ }^{3}$

\section{RESUMO}

Estudo histórico-social, que teve como objetivo a análise da influência germânica no campo da saúde nos primórdios da enfermagem profissional na cidade do Recife, Pernambuco. Foi feita análise do conteúdo dos documentos à luz do pensamento de Bourdieu. Na interpretação dos dados, a noção de campo e poder foi utilizada de modo a contemplar as forças que contribuem para a formação do campo organizacional da enfermagem. 0 recorte temporal foi de 1924, com a vinda das enfermeiras alemãs para trabalhar no Hospital do Centenário (HC), até 1927, quando ocorre a saída da enfermeira administradora. Utilizaram-se fontes primárias e secundárias. Como resultado, observa-se que a cultura alemã exerceu forte influência no campo da saúde, comércio, indústria, economia e educação. A influência se dá nos primórdios da enfermagem profissional pelo reconhecimento da atuação das enfermeiras pela dedicação e abnegação aos enfermos no trabalho que desenvolviam.

Palavras-chave: História da Enfermagem. Alemanha. Cuidados de Enfermagem

\begin{abstract}
The objective of this study the analyses of the Germanic influence in the health field and its reflections in the early days of professional nursing. It is a social and historical study which is based on the theories of Bourdieu deeply exploring his concept of field and power. The time period chosen for analysis was from 1924, with the arrival of German nurses to work in the Hospital do Centenário (HC) until 1927, when the nurse manager left his position. It was used primary and secondary sources. As a result, it seems that German culture was a strong influence in health, business, industry, economy and education. The influence in the early days of professional nursing is giving the recognition of the role of nurses by the dedication and self-denial by patients and their work.
\end{abstract}

Keywords: History of Nursing. Germany. Nursing Care.

\begin{abstract}
Resumen
Estudio histórico-social, que tuvo como objetivo el análisis de la influencia germánica en el campo de la salud en los inicios de la enfermería profesional en la ciudad de Recife, Pernambuco. Fue realizado el análisis del contenido de los documentos bajo la óptica del pensamiento de Bourdieu. En la interpretación de los datos las nociones de campo y poder fueron utilizadas como forma de contemplar las fuerzas que contribuyen a la formación del campo organizacional de la enfermería. El corte de tiempo se produjo en 1924, con la llegada de las enfermeras alemanas para trabajar en el Hospital del Centenario (HC) y se extendió hasta 1927, donde se presenta la salida de la enfermera administradora. Se utilizaron fuentes primarias y secundarias. Como resultado, se observa que la cultura alemana ejerció una fuerte influencia en el campo de la salud, en el comercio, industria, economía y educación. La influencia se presenta en los inicios de la enfermería profesional con el reconocimiento de la actuación de las enfermeras, debido a su abnegación y dedicación a los enfermos en el trabajo que desarrollaban.
\end{abstract}

Palabras clave: Historia de la Enfermería. Alemania. Atención de Enfermería.

\footnotetext{
${ }^{1}$ Doutora em Enfermagem. Professora Adjunta da Faculdade de Enfermagem Nossa Senhora das Graças/UPE. Membro do NUPHEBRÄS e do Grupo de Estudos e Pesquisa em Epistemologia e Fundamentos do Cuidar na Saúde e Enfermagem (GEPEfuncsenf). Coordenadora do Programa Associado de Pós-graduação em Enfermagem UPE/UEPB (PAPGenf-UPE/UEPB). Brasil. E-mail: fatimabrao@br.inter.net, fatimabrao@terra.com.br, ${ }^{2}$ Professor Adjunta da Faculdade de Enfermagem Nossa Senhora das Graças/UPE. Coordenadora de Pós-graduação da FENSG/UPE. Membro do GEPEfuncsenf. Brasil. E-mail: reginac_oliveira@terra.com.br, ${ }^{3}$ Aluna do Curso de Graduação em Enfermagem da FENSG/UPE. Bolsista PIBIC/CNPq/UPE. Brasil. E-mail: natally_freitas84@hotmail.com, ${ }^{4}$. Aluna do Curso de Graduação em Enfermagem da FENSG/UPE. Bolsista PIBIC/UPE. Brasil. E-mail: ninycosta@yahoo.com.br, ${ }^{5}$ Aluna do Curso de Graduação em enfermagem da FENSG/UPE. Bolsista PIBIC/UPE. Brasil. E-mail: nessinha_smile11@hotmail.com
} 


\section{INTRODUCÃO}

0 entendimento a respeito da influência alemã na cultura pernambucana, e no campo da saúde, bem como a influência no processo de institucionalização da enfermagem nos remete a uma análise e descrição dos fatos e acontecimentos que contribuíram para a fusão cultural germânico-brasileira, remontando fatos desde a chegada dos alemães ao país, que data da "Era Quinhentista", da Vera Cruz, do nascimento do "Brasilland"1, para promover uma melhor compreensão do processo de consolidação da presença germânica em terras pernambucanas e sua expansão cultural no estado e no país.

0 encontro da cultura luso-europeia com o lusotropicalismo emergente acarretou grandes influências as quais foram recíprocas, pois tanto o Brasil quanto a Alemanha se beneficiaram nesse processo de miscigenação de culturas.

0 legado deixado pelos imigrantes alemães inserese em vários aspectos, podendo inclusive ser agrupado em cinco grandes eixos que permeiam o ensino, a pesquisa e a ciência; a economia e o desenvolvimento, e inseridos nestes desmembra-se o enfoque ao setor saúde, e, mais especificamente, à profissão de Enfermagem.

No Brasil, as relações com a Europa germânica tiveram seu começo em Pernambuco e foram aqui consideráveis no decorrer do século XIX, germanizando todos os âmbitos da sociedade pernambucana ${ }^{2}$. A influência germânica no Brasil se fortaleceu e contribui em grande medida para a formação cultural do país.

A influência germânica também se estendeu ao campo da educação, sob as áreas do Direito, Filosofia, Crítica de idéias e Literatura, na Escola do Recife, contribuindo para a construção e modernização do pensamento cientifico ${ }^{2}$, além do campo da saúde.

Sendo assim, convém destacar a importância das missionárias beneditinas de Tutzing da Baviera — região que faz fronteira com a Alemanha - , além de outras irmãs alemãs. Instalando-se no velho Casarão de Olinda, no início do século $X X$, as religiosas tiveram o desejo de proporcionar um ensino voltado para estudantes do sexo feminino com cursos ginasiais, colegiais e pedagógicos ao fundar o educandário "Academia Santa Gertrudes". 3

Em 1904, a pedido do abade Dom Gerardo, as irmãs começaram com os cuidados aos doentes pobres em domićlio. Neste mesmo período, muitos livros de medicina e enfermagem foram trazidos por elas para o Brasil. Vale salientar a existência de uma das irmãs beneditinas que era enfermeira, Ir. Hiltrudes Herz (OSB), que prestou, na época, cuidado domiciliar a um conterrâneo em Recife até ele se recuperar para voltar a Alemanha. Este fato, que pode ser constatado a partir dos relatos da Irmã Hidegardis Nassen (OSB) ${ }^{3}$, aponta indícios de uma possível influência germânica no campo da saúde e revela a atuação de Enfermagem em termos de assistência domiciliar no Estado.

No campo da educação, D. Pedro Roeser, beneditino alemão, sucessor de Dom Geraldo van Caloen, bispo de Olinda, fundou, em 1912, na referida cidade, a Escola de Agronomia e Veterinária, hoje Universidade Rural de Pernambuco³, possibilitando a vinda do veterinário $\mathrm{Dr}$. Roesler ${ }^{1}$, formando-se em Medicina no estado da Bahia posteriormente. Também Ihe é atribuída a fundação do Instituto do Radium, órgão que divulgou mais veementemente a aplicação dos raios $X$ de Roentgen. ${ }^{1}$ Sob nosso olhar, esses eventos devem também ser considerados como indícios da influência germânica no campo da saúde em Pernambuco. ${ }^{3}$

Essa influência germânica, em seus aspectos culturais e científicos, não foi diferente no campo da Enfermagem, principalmente no que se refere às contribuições dadas em Pernambuco, à época da implantação do Hospital do Centenário (HC), considerado ambiente institucional. Para o $\mathrm{HC}$ vieram as enfermeiras alemãs para administrar e também contribuir, acredita-se, para implantação de uma Escola para Enfermeiras, tendo como seu mentor D. Pedro Roeser. ${ }^{3}$

Considerando que os estudos que têm como foco de análise as raízes da Enfermagem profissional na cidade do Recife ainda são poucos, principalmente no que diz respeito à influência germânica no campo da saúde nessa época, em 1924 foi que surgiu a necessidade da realização desta pesquisa. Os achados que se fazem presentes estimulam e possibilitam o entendimento acerca da formação do futuro campo organizacional da enfermagem e o seu processo de institucionalização, no entanto, carecem ainda de análises que o complementem, buscando o modelo de enfermagem deixado pelas enfermeiras alemãs que vieram para o Recife, com o compromisso de trabalhar no HC.

Os trabalhos, na historiografia no Brasil e em Pernambuco, que apontam para questões que se remetem à influência germânica nesse sentido, são poucos. Com este estudo, foi possível vislumbrar a presença germânica em diversos setores de atividade, mas principalmente no processo de profissionalização da Enfermagem.

0 objetivo deste trabalho foi analisar a influência germânica no campo da saúde nos primórdios da enfermagem profissional na cidade do Recife, Pernambuco. 


\section{METODOLOGIA}

Este estudo histórico-social tem um recorte temporal que percorre os anos de 1924 a 1927, tendo em vista que é no ano 1924 que ocorre a vinda das enfermeiras alemãs para trabalhar no Hospital do Centenário e em 1927 a saída por falecimento de uma dessas enfermeiras que é também a administradora.

Ao utilizar o pensamento de Pierre Bourdieu, a análise da discussão dos conteúdos e discursos dos agentes levou à interpretação necessária para contemplar a influência germânica nos primórdios da enfermagem profissional, ampliando os conhecimentos do futuro campo organizacional da enfermagem profissional e o seu processo de institucionalização. ${ }^{3}$

Para o estudo foram utilizados os discursos dos agentes que faziam parte do campo da saúde na época. Foram eles: 0 beneditino alemão Pedro Roeser, que lançou a ideia da criação de uma Escola de Enfermeiras; Fernando Simões Barbosa, que participou de um movimento para criação de um hospital modelo, no qual teria em anexo uma Escola de Enfermeiras que fora idealizada por Pedro Roeser.

Outro agente importante foi Amaury de Medeiros, diretor do Departamento de Saúde e Assistência, no governo de Sérgio Loreto, que, com sua reforma sanitária, apoiou o hospital modelo e criou também uma Escola de Visitadoras de Saúde Pública, tendo inclusive participado de congressos e cursos na Alemanha.

Esta investigação se valeu de fontes primárias e secundárias. As fontes primárias foram extraídas dos conteúdos de documentos e dos jornais da época, como o Jornal do Comércio, o Diário de Pernambuco, a Revista de Pernambuco e o Almanaque de Pernambuco, periódicos nos quais se vislumbrou os agentes no campo da saúde, e em outras áreas, envolvidos na criação e implantação do Hospital do Centenário. As fontes secundárias foram extraídas de artigos e livros da historiografia brasileira, internacional e local.

Sendo um estudo histórico-social (ou seja, não se tratando de pesquisa com seres humanos, mas atendendo um protocolo de pesquisa e à portaria 196/96 MS), enquadra-se no projeto de pesquisa, iniciado em 2002, intitulado: Primórdios da Enfermagem Profissional na cidade do Recife, Pernambuco (1922-1945), que recebeu o parecer favorável do Comitê de Ética em Pesquisa do Centro Integrado de Saúde Amaury de Medeiros (CISAM) em 11 de maio de 2005.

Os dados foram analisados e interpretados a partir dos discursos dos agentes contidos nos conteúdos presentes nos documentos e nos jornais supracitados. No momento da leitura, temas como: saúde, enfermeiras alemãs e alemãs no Recife, que estavam relacionados ao nosso objeto de estudo a influência germânica nas áreas de enfermagem e saúde na cidade do Recife - foram identificados para nortear a interpretação.

Dos dados obtidos das temáticas inicialmente identificadas, percebe-se que a área da saúde era rica de discursos que apontavam alguma forma de influência exercida por agentes. Como na época, 1925, a Enfermagem era apenas um campo emergente, optou-se por considerar, de acordo com estudo já realizado ${ }^{3}$, o Hospital do Centenário (HC) como ambiente institucional e ponto de demarcação para os primórdios da enfermagem profissional na cidade do Recife, no estado de Pernambuco.

Sendo assim, serão ressaltadas categorias que permitam melhor convergência dos temas, sua compreensão, análise e interpretação de acordo com o objetivo proposto

\section{RESULTADO E DISCUSSÃO}

\section{Influência germânica no campo da saúde}

A cultura alemã na cidade do Recife foi de extrema importância, no sentido de contribuir para aprimorar, inovar e acrescentar no que em Recife já havia de bom, seja nos trabalhos e inovação nos engenhos de açúcar, na cultura pernambucana, na geografia recifense de belos recortes e formas, como também no cotidiano dos cidadãos e habitantes de Pernambuco.

0 evento que influenciou o campo da saúde, e que foi destaque para época, foi a criação de um Hospital Modelo e a vinda das enfermeiras alemãs para Pernambuco em dezembro de 1924. A pedra fundamental desse grande Hospital Modelo foi lançada em 7 de setembro de 1922 e sua inauguração realizou-se em 3 de maio de 1925. Esse hospital foi denominado Hospital do Centenário ( $\mathrm{HC}$ ) em comemoração ao centenário da Independência.

Não se pode deixar de falar da influência germânica no campo da saúde e nos primórdios da enfermagem sem deixar de compreender o Hospital do Centenário ${ }^{3}$, doravante HC, como instrumento de profissionalização e implantação de um serviço de Enfermagem de alto-padrão para a época. Foi uma instituição com grande respaldo para a sociedade e que marcou as raízes da história da Enfermagem em Pernambuco.

A inauguração do $\mathrm{HC}$ foi extremamente noticiada por meios de comunicação. $0 \mathrm{HC}$ foi um empreendimento dos médicos que constituiu o maior exemplo na época de organização e ato de solidariedade e apoio recebido.

Além disso, foi a partir dele que se iniciou a organização das atividades de Enfermagem na cidade do Recife, no âmbito 
da saúde e da educação. Dessa forma, o campo da saúde tornase palco de um "jogo de poder" capaz de transformar e influenciar uma prática. No campo de poder há relações de forças entre as posições sociais, garantindo aos agentes um capital, possibilitador de sua entrada na luta pelo monopólio. ${ }^{4}$

Havia vários interesses que mobilizaram e determinaram a construção do HC, dentre eles a necessidade da construção de um Hospital das Clínicas na cidade, pelo médico Dr. José Mendonça; e a pretensão da instalação de um hospital anexo à faculdade de Medicina, então recém-inaugurada pelo Dr. Armando Gayoso,

0 desejo do Dr. Fernando Simões Barbosa de construir um Instituto Policlínico ${ }^{5}$ e um hospital na cidade e o anseio da criação de um hospital, pelo padre beneditino alemão de Olinda, D. Pedro Roeser, para sediar uma Escola de Enfermeiras, contribuíram para que o estado de Pernambuco pudesse contar com profissionais qualificados e eficientes no referido ramo.

Nesse sentido, D. Pedro Roeser foi o principal ativista na criação do $\mathrm{HC}, \mathrm{e}$, junto com ele, os médicos Fernando e Adolpho Simões Barbosa, foram os representantes de maior destaque e prestígio da sociedade da época, o que contribuiu para o surgimento de novos adeptos e acúmulo de capital simbólico ${ }^{3,4}$ no período.

Com relação ao status de saúde no Brasil durante o século XX, os agentes, em seus discursos, em busca de tecnologias de saúde, ressaltavam a cidade do Recife como cenário para conquistas sanitárias importantes, baseadas em políticas higienistas e progresso urbano. Além disso, pretendiam a melhoria dos serviços de saúde e modernização das práticas

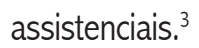

Um dos grandes agentes de destaque no campo da saúde ligada à higiene em Pernambuco foi o médico Amaury de Medeiros, diretor do Departamento de Saúde e Assistência e presidente da Sociedade de Medicina, que também contribuiu de forma bastante significativa para a construção do HC. Foram relevantes os serviços desse departamento sob a sua coordenação, começando pelo combate a epidemias com melhoria das instalações hospitalares, constituindo o $\mathrm{HC}$ um diferencial de sua gestão, o que parece ter também motivado a vinda das chamadas enfermeiras alemãs. ${ }^{3}$

Além de ter sido o país de origem das onze enfermeiras que aqui desembarcaram para colaborar com os serviços do grande hospital, da Alemanha também foram trazidas inúmeras máquinas, acessórios para cirurgia, objetos de construção, substâncias para narcose, equipamentos, entre outros instrumentos necessários para a formação tecnológica do $H C$. 6:186
Foi inaugurado hontem, esse importante estabelecimento - A missa campal, e os discursos — Várias notas [...]. Todos os salões estão construídos com os necessários requisitos modernos [...]. No outro salão foi montada uma mesa operatória allemã, do fabricante Borchardt [...]. Também na secção de cirurgia contam-se dois vestiários e a sala de material cirúrgico com o melhor e mais aperfeiçoado instrumental, adquirido nos centros mais adeantados da Europa [...]. A pharmacia também está rigorosamente instalada, obedecendo à direção da pharmaceutica allemã $d$. Elizabeth Popp. Será uma das suas fontes de renda [...]. A grande cosinha do hospital é allemã e a vapor, dispondo de uma lavanderia franceza, a melhor do mundo.

Por outro lado, observa-se ainda destaque sobre as instalações e serviços do grande hospital modelo 6:185

Em cada uma das duas últimas salas de operação, está montada uma poderosa lâmpada para iluminação artificial que evita sombra; aparelhos moderníssimos para narcose. Pela descrição das instalações, dos equipamentos, aliás, diga-se de passagem, o instrumental cirúrgico não foi registrado pelo noticiário dos jornais. Todo ele foi de procedência alemã, certamente abundante.

0 jornal da época, 1922 enfocava uma assistência deficiente aos doentes da cidade ${ }^{7: 2}$

\begin{abstract}
No Recife, ainda hoje, mal de grado tudo quando se tem em materia hospitalar, sente-se a deficiencia, que vai à penuria, de um serviço de assistencia aos doentes. 0 que ha é primitivo, remonta ainda a época imperial e não condiz de modo algum como surto progressivo da nossa capital. Dahi a dizer-se, com fundamento, que aqui se morre, a falta de hospitaes e casas de saúde.
\end{abstract}

Destaca-se a relevância de que bens e serviços fossem oferecidos com qualidade, por meio da construção e desenvolvimento de ações com surgimento de hospitais e escolas ou programas que fossem relacionados à sociedade como um todo. ${ }^{6}$ Logo, a Alemanha foi tomada como referencial em tecnologia, ciência e serviços médicos para o Hospital do 
Centenário, uma vez que este era um dos países, junto com os Estados Unidos, que mais se sobressaía nesses ramos.

A Alemanha era um país tido como "exemplo de prestação de serviços médicos", dispondo de alta tecnologia em sua estrutura terapêutica e transmitindo uma imagem de "estado de seguridade social" com alta capacidade de intervenção nos processos de saúde-doença de sua população. ${ }^{8}$

Os agentes da época, como o abade D. Pedro Roeser e Fernando Simões Barbosa, por seus status sociais, tinham diversos contatos estrangeiros, principalmente na Alemanha, 0 que pode ter contribuído para a criação do Hospital do Centenário nos moldes alemães. ${ }^{3}$ Isso pode ser percebido a partir do convite realizado pelo beneditino $D$. Pedro para que um médico alemão, o Dr. Ernesto Roesler, coordenasse a construção do novo hospital.

$0 \mathrm{HC}$, com o passar do tempo, foi enfrentando dificuldades, mesmo contando ainda com um eficiente quadro de funcionários. Tornou-se quase impossível manter o HC como o hospital modelo tão sonhado e planejado. Em 1937, o Estado fez intervenção no HC, bem como em outros hospitais, e exerceu sobre ele sua posse. Esse hospital, de qualquer modo, marcou em Pernambuco uma nova era na medicina, na cirurgia e na organização hospitalar. ${ }^{5}$

A partir de todos os aspectos apontados, foi possível observar de que modo o campo da saúde sofreu forte influência germânica, tendo o HC como um ambiente institucional e um campo de luta ${ }^{4}$ para a formação de um campo emergente para a enfermagem. ${ }^{3}$

\section{Influência Germânica no campo emergente da enfermagem}

As práticas de enfermagem, no início do século XX, no Brasil, eram desenvolvidas por pessoas leigas, irmãs de caridade e pessoas com treinamento ministrado por médicos, ligados a diversas instituiç̧ões hospitalares, fato que se repetia também em Recife, Pernambuco. ${ }^{3}$

Para a capital da República, na década de XX, vieram enfermeiras americanas e adaptaram o modelo anglo-americano de enfermagem à realidade brasileira,, 10 enquanto, para 0 Recife, vieram enfermeiras alemãs.

A precariedade do serviço de enfermagem na cidade pernambucana já era evidenciada em notícias de jornais de circulação da época ${ }^{11: 4}$

A profissão de enfermeira — não temos pessoal habilitado nos nosocômios [...]. Os nosocomios, quer públicos ou particulares, lutam com grande dificuldade para encontrar enfermeiros, auxiliares sem os quaes não é possível o regular funccionamento de qualquer fundação no gênero. $\mathrm{Si}$, abstrairmos dos serviços as irmãs de caridade, teremos, forçosamente, de recorrer ao estrangeiro. Em Pernambuco, installado ultimamente o Hospital do Centenário, foi necessário mandar vir profissionais allemãs.

Em discurso no lançamento da Pedra Fundamental do Hospital do Centenário tem-se o seguinte ${ }^{7: 2}$ :

Abrindo a sessão o revmo. Abbade d. Pedro leu
eloqüente discurso historiando a iniciativa
humanitária que promete ser coroada do melhor
êxito. S. revmo. disse como Ihe veio, na cabeceira
de doentes, a idéia de uma escola de enfermeiras
nesta capital. Em casos freqüentes de um
prolongado soffrimento do ente querido, quando já
se acham eshaustas as pessoas da familia, surgem
estes anjos de caridade, — as enfermeiras
profissionais, que vêm compartilhar de árdua tarefa
piedosa.

Também era a pretensão do médico Fernando Simões Barbosa a aquisição de enfermeiras de alto padrão para a prestação de serviços nesse hospital, as quais poderiam ser encontradas na Alemanha, um dos países orientadores da medicina brasileira daquele tempo.

Em 1836, na província alemã de Kaiserswerth, foi fundada a primeira Escola de Enfermagem na qual um currículo teórico prático deveria ser cumprido e um exame final era aplicado para a conclusão do curso. ${ }^{8}$ Foi implantada a primeira escola para assistência de enfermagem em 1782.

No estado brasileiro de Santa Catarina, os descendentes alemães estudavam em escolas de origem alemã, e era comum que enviassem suas filhas para conhecerem e trabalharem em instituições de saúde e ensino. $^{12}$

Onze enfermeiras alemãs chegaram ao Recife no dia 26 de dezembro de 1924, a bordo do navio holandês "Flandria". Nessa época, a comunidade alemã já era forte no Estado. Essas enfermeiras, sob a chefia de Anna Schüller, vieram com o propósito de administrar o HC, no Recife. Pertenciam à Cruz Vermelha Transatlântica Alemã ${ }^{5}$, tendo chegado antes da primeira turma de enfermeiras diplomadas pela Escola Ana Nery, no Rio de Janeiro, que só ocorreu em 1925. 0 intuito era que elas contribuíssem para a formação do campo de enfermagem. ${ }^{3}$ 
Em 1924, o Jornal do Comércio, na sessão Notícias Marítimas, trazia uma matéria intitulada o "Flandria" que noticiava o acontecimento ${ }^{13: 2}$

Vindo de Amsterdam com escala por Southamptom, Cherbourg, Coruna, Vigo, Leixões, Lisboa e Las Palmas, passou hontem, por nosso porto, com 18 dias de viagem, o paquete Flandria, do Lloyd Real Hollandez, que atracou ao armazém 2 das Docas. Para o Recife trouxe o referido paquete 24 passageiros, inclusive 11 enfermeiras alemãs para o Hospital do Centenário, desta cidade.

Entre os passageiros do Flandria, estavam as enfermeiras alemãs ${ }^{3}$ Anna Schüller, Elisabeth Popp, Margarete Heck, Ceuta Grable, Maria Maier, Maria Reichenback, Bertha Licht, Eva Brunnengraber e Aloysia Heiler (Alice Heiler), Frieda Schoch, Elisabeth Zipfel.

As enfermeiras alemãs que vieram trabalhar no $\mathrm{HC}$ eram pertencentes à geração anterior à grande guerra de 1914 da Alemanha, tinham uma educação muito boa, uma ótima formação técnica, tanto teórica como prática, com estágio em bons hospitais na Alemanha, eram católicas pertencentes a uma organização também católica: a Cruz Vermelha Transatlântica Alemã̃; muitas delas prestaram bons serviços nos hospitais de sangue durante o referido grande conflito mundial.

Nesta pesquisa, questiona-se ainda a escolha de enfermeiras alemãs para o trabalho no $\mathrm{HC}$, em vez de enfermeiras de outros países, como dos Estados Unidos, por exemplo (como aconteceu no Rio de Janeiro, para onde, com a Reforma Carlos Chagas, foram, para o hospital São Francisco de Assis, enfermeiras norte-americanas).

A Alemanha foi um centro formador de alto padrão da organização do HC, e no Recife havia uma forte influência germânica no campo da saúde; com isso, acredita-se que ocorreu a vinda das onze enfermeiras diplomadas, integrantes da Cruz Vermelha Alemã, todas formadas por institutos alemães, bem treinadas e instruídas.

Além disso, os agentes da época, como o abade beneditino D. Pedro Roeser, Fernando Simões Barbosa e Adolpho Simões Barbosa, os quais estavam à frente na direção do hospital, detinham um capital simbólico ${ }^{4}$ significativo e se destacavam naquilo que faziam.

Pedro Roeser, no âmbito da religião, fundamentado pela Igreja Católica, e Simões Barbosa e Amaury de Medeiros, no âmbito dos serviços médicos, eram pessoas com vivência em diversos outros países e com elevado grau de formação acadêmica, o que pode ter contribuído para que tivessem criado contatos em países estrangeiros e principalmente na Alemanha; na oportunidade da criação do Hospital do Centenário, recorreram à Alemanha tomando-a como fonte de mão-deobra e de tecnologia ${ }^{3}$.

A qualidade, dedicação e competência do corpo de Enfermagem alemã, as marcas evidentes de sua presença com seus luxuosos aposentos e brancura de seu fardamento, passavam uma imagem de saúde e felicidade, além do que deixava transparecer que "talvez o HC fosse o único hospital nacional que possuísse complexo serviço de enfermeiras" $5: 365$.

Além disso, os jornais fazem referência aos modos pelos quais essas enfermeiras tratavam os enfermos, sempre com muita solicitude e atenção, como também destaca o papel da enfermeira-chefe, a qual "expedia ordens para todos os cantos"5:366.

A enfermeira de maior destaque, sem dúvida, foi Anna Schüller, enfermeira administradora do hospital. Havia destaque em jornal da época para as virtudes e carreira da enfermeira superiora Anna Schüller ${ }^{14: 3}$

Esta senhora tem um bello tirocínio, na sua especialidade. Começou o curso na Casa da Cruz Vermelha, em Karlsrush e, após diplomar-se como enfermeira, trabalhou, durante três annos, no Hospital Municipal daquella cidade, em medicina interna e cirurgia. Durante a grande guerra, serviu nos hospitais de sangue. Esteve três annos e meio como superiora geral do Hospital de crianças de Berlim dirigido pelo professor Niemarum; e quatro annos, como superiora do Grande Hospital de mulheres de Friburgo, sul da Allemanha.

Nascida em 1876, em Adellesheim, na Alemanha, Anna Schüller faleceu no Hospital do Centenário com 51 anos, após rápida doença em 9 de abril de 1927, aproximadamente 3 anos após sua chegada a Pernambuco. Vários jornais da época noticiaram com muito pesar e sentimento a partida dessa enfermeira que desempenhou com extrema honra e competência a sua profissão. ${ }^{5}$

Não se pode deixar de mencionar a passagem de Florence Nightingale, em 1850, pela Escola de Enfermagem na Alemanha, na qual realizou um curso de formação com duração de três meses. 0 legado que as enfermeiras alemãs deixaram para a Enfermagem em Pernambuco ainda carece de estudos. No entanto, a forma como tratavam os doentes mostra o preparo e o exemplo de amor e dedicação para com eles. $^{3}$ 
Como as enfermeiras chegaram antes da inauguração do HC, trabalharam com dedicação na sua organização e montagem de suas instalações: "As enfermeiras residem num annexo ao Hospital confortavelmente preparado. Obedecem a direção de D. Anna Schüller, administradora do Hospital"15:3.

A assistência qualificada e humanizada dessas enfermeiras pode ser observada em relatos que foram transcritos da seguinte maneira ${ }^{5: 10}$ :

O serviço de enfermeiras do HC é admirável, ellas têm, ahi, lançado as bases de sua profissão, dedicando ver 0 adextro de suas mãos ao velar delicadamente um doente no leito, ao aconchegarIhe um travesseiro ao alliviar-lhe as dores. Impressionam veramente a dedicação, a vontade, a intelligencia dessas moças.

De acordo com o relatório apresentado aos membros do Conselho Deliberativo da Associação Mantenedora do Hospital do Centenário ${ }^{3}$, Pedro Roeser foi elogiado na escolha e seleção das enfermeiras alemãs, selecionando o que ali havia de competência e de bom coração. Além disso, foram enfatizados os sentimentos de bondade e caridade transmitidos por essas almas caridosas, como também o carinho e dedicação com que tratam os doentes, ${ }^{5}$ sendo notória a atuação de Ana Schüller.

Pelo que se observa em depoimentos e referências sobre Anna Schüller, esta serviu com grande zelo e dedicação ao ofício de sua profissão e ao exercício da prática de enfermagem em prol do serviço aos necessitados de saúde. Em sua terra natal foi grande exemplo de patriotismo, se destacando durante o período de guerra 16,5: "D. Anna Schüller serviu, durante a grande guerra, como enfermeira, na França e na Bélgica, esbanjando provas de seu desprendimento pela causa que abraçou."

E, mesmo sendo estrangeira, desconhecida entre os habitantes de Pernambuco, se mostrou digna de respeito e compromissada com seu ideal, inclusive firmando grandes amizades no território: "Natural de Adelleshein, na Allemanha, onde nasceu em 1876, transportara-se a extincta para o Brasil, tendo fixado residência nesta capital em cuja sociedade granjeou largo círculo de relações"16:3.

Schüller, ao vir para Pernambuco, logo no início, já ocupou um cargo importante, sendo reconhecida como administradora do Hospital do Centenário e superiora do corpo de Enfermagem. 0 papel dessa enfermeira perante a sociedade era de destaque, o que não condiz com a imagem histórica da Enfermagem como profissão de submissão médica. Leva-nos a crer que, por sua história profissional, suas experiências em
Abrão FMS, Oliveira RC, Freitas N, Costa NFCG, Sales VMB

seu país de origem e sua dedicação e exemplo de caridade, essa mulher tenha dado à Enfermagem um outro sentido, juntamente com as outras dez enfermeiras que vieram consigo. ${ }^{3}$

Outro aspecto que merece atenção é que, provavelmente, na distribuição dos cargos às enfermeiras no $\mathrm{HC}$, estas foram selecionadas para cada setor específico, mediante seu conhecimento prévio, adquirido em suas experiências e carreira profissional na Alemanha. Isso mostra que elas poderiam exercer a profissão com maior qualidade e eficiência.

Neste contexto, vale salientar o papel importante que o médico Amaury de Medeiros desempenhou à frente do Departamento de Saúde e Assistência da cidade do Recife, instituindo o Curso de Visitadoras de Saúde Pública em 1923 17,3 , sendo um agente que recebeu e compartilhou informações com a comunidade médica alemã quando era membro da Cruz Vermelha Brasileira e apoiando a criação do hospital modelo.

0 discurso de abertura do Curso, executado por Amaury de Medeiros, foi bastante divulgado. Este enfocava a importância da visitadora nos serviços sanitários, associandoos ao ofício da enfermagem..$^{18} 0$ mesmo discurso ressaltava ainda que, nos primeiros tempos, a assistência dada aos doentes era exercida por homens e mulheres, ligeiramente habilitados para o serviço nos hospitais, e por senhoras de caridade que não tinham conhecimento algum de higiene, mas que procuravam dar consolo aos doentes. Enaltece os serviços das enfermeiras da Cruz Vermelha Alemã ${ }^{18}$, na prestação de cuidados aos flagelados de guerra.

Foi por este motivo, para melhor amparar essas mulheres, que surgiu a necessidade, por parte dos paises europeus, da criação de Escola de Enfermeiras.

Isto leva a crer que o modelo de Enfermagem na Alemanha tenha inspirado o médico Amaury de Medeiros a idealizar o Curso de Visitadoras de Saúde Pública, como também influenciado as atividades do Departamento de Saúde e Assistência. Além disso, esse agente pode ter tido um papel importante no processo de criação do Hospital do Centenário.

Por ser um ilustre médico que ocupava uma posição de destaque na sociedade pernambucana e também em outros países, e, por ser um homem conhecedor de culturas diversas, pode ele ter contribuído para a vinda de médicos, enfermeiras e outros profissionais da Alemanha, além de ter facilitado a chegada no Hospital de maquinário e instrumentação alemã, necessária para a montagem de todo o serviço do $\mathrm{HC}^{3}$.

No $\mathrm{HC}$, apenas funcionou o curso de formação para enfermeiras práticas. Talvez isso seja o que se possa chamar de curso prático de Enfermagem. Ainda não foi dessa vez 


\section{CONSIDERAÇÕES FINAIS}

A influência germânica tem sido contemplada em todos os aspectos não só cultural como no campo da saúde. A influência alemã na cidade do Recife, Pernambuco, exercida pelos agentes envolvidos na área do Ensino, Pesquisa, Ciência e Economia, proporcionou à população não só pernambucana, mas brasileira, um legado cultural e intelectual de grande valia para 0 desenvolvimento do país.

Tendo como base fatos e relatos de jornais e documentos apresentados nesse estudo, cremos que tornouse necessária, a partir dos anseios dos agentes na época, a criação de um hospital modelo, de tecnologia de ponta. Isso tudo, tendo em vista que a cidade do Recife apresentava uma assistência médica deficiente, tanto em relação a equipamentos terapêuticos de boa qualidade como em infraestrutura associada à escassez na quantidade e qualidade dos profissionais.

Sendo a Alemanha a referência no que diz respeito à modernidade e qualidade da assistência, houve a possibilidade concreta do intercâmbio de profissionais, além da utilização em maquinário, instrumentais, peças e acessórios para o $\mathrm{HC}$ em Recife. Sendo assim, o Hospital do Centenário foi enormemente elogiado e ganhou prestígio por sua excelência de instalação, a eficiência de sua aparelhagem, refletida na escolha do corpo administrativo, clínico e de enfermagem, atendendo às expectativas dos seus idealizadores.

Não se pode deixar também de falar da influência germânica, sem deixar de compreender, nos primórdios da Enfermagem Profissional, o estabelecimento de esforços em busca da profissionalização e implantação de um serviço de Enfermagem de alto padrão para a época. Foi o HC, sem dúvida, um ambiente institucional com respaldo da sociedade e do governo do Estado, marcando as raízes da história da Enfermagem na cidade do Recife.

A isso, soma-se a imagem que a Enfermagem trouxe para aquela sociedade, uma vez que, na figura representativa de Anna Schüller, enfermeira de grande capacidade e detentora de um poder simbólico, revelou-se a eficiência e a dedicação. Observa-se que, a partir de tal revelação, já pode ser observado o primeiro vestígio da mudança de conceito da enfermagem - que anteriormente estava associado à execução de tarefas meramente assistenciais e de submissão ao profissional médico — atribuindo a ele autonomia, um poder científico e de valor.

A presença alemã no Recife não forneceu dados puramente incisivos e concretos de um modelo de enfermagem deixado pelas enfermeiras alemãs. Entretanto, diante de todos os dados analisados, conclú́mos que o legado da enfermagem alemã deve-se à fusão do modelo de enfermagem exercido na
Alemanha com as práticas de Enfermagem que já existiam na cidade do Recife, que eram executadas por profissionais despreparados e de educação rudimentar e, muitas vezes, capacitados pelos próprios médicos.

Com a chegada das enfermeiras alemãs, em especial de Ana Schüller, fica registrada, pela primeira vez, uma função de enfermagem que até então não havia sido mencionada que consiste em uma administração hospitalar e de pessoal peculiar — devida, em grande parte, à competência, aos esforços e ao empenho dessa profissional, com uma grande carga de conhecimento e prática talvez antes nunca alcançados. Além disso, neste mesmo contexto, observam-se evidências da criação de uma possível escola para formadores de profissionais em Enfermagem.

As formas de cuidar, de se relacionar, de atender aos enfermos não foram suficientes para que a sociedade as reconhecesse plenamente como profissionais. Provavelmente, as enfermeiras alemãs que exerciam a enfermagem puderam contribuir para a ciência, a partir das práticas e condutas utilizadas, deixando a área hospitalar com uma enfermagem mais bem preparada.

\section{REFERÊNCIAS}

1.Schmalz AC. Alemães em Pernambuco. Recife (PE); 1966. Coleção Katloon, 4.

2.Freyre G. Nós e Europa germânica: em torno de alguns aspectos das relações do Brasil com a cultura germânica no decorrer do século XIX. Rio de Janeiro (RJ): Grifo; 1971

3.Abrão FMS, Almeida MCP. Primórdios da enfermagem profissional na cidade do Recife, Pernambuco: raízes da pré-institucionalização da formação do campo organizacional (1922 - 1938). Recife (PE): EDUPE; 2007.

4.Bourdieu P. 0 poder simbólico. Rio de Janeiro (RJ): Bertrand; 1989.

5.Ramos HP. Subsídios para a história da enfermagem em Pernambuco: primeiras pioneiras da enfermagem. Separata dos Anais da Academia de Medicina. Recife (PE); 1977.

6. Costa V. Medicina, Pernambuco e tempo. Recife (PE): Fundação de Cultura da cidade do Recife; 1983.

7.A Fundação do Hospital Modelo. Jornal do Comércio, Recife, 1922 maio; $17 ;(1): 2$.

8.Kleba ME. A enfermagem na Alemanha: algumas reflexões sobre sua constituição histórica e o processo atual de profissionalização. Rev Latino-am Enfermagem 1996; 4(3): 117-33. 
9. Oliveira CS, Barreira, IA. A $2^{\text {a }}$ guerra mundial e o retorno das americanas ao Brasil. Esc Anna Nery Rev Enferm 2000 ago; 4(2): 209-16.

10. Barreira IA. Os primórdios da enfermagem moderna no Brasil. Esc Anna Nery Rev Enferm 1997 jul; 1 (n. esp): 161-76.

11. Hospital Centenário. Diário de Pernambuco, Recife, 1927 jan; 25(1): 4.

12. Borenstein MS, Padilha MI, Caetano TL, Mancia JR. Hilda Anna Krisch: pioneira na enfermagem catarinense-formação e contribuição. Rev Bras Enferm 2004 maio/jun; 57(3): 366-70.

13. D. Pedro Roeser. Viajantes. Diário de Pernambuco, Recife, 1924 dez; 27(1): 2 .

14. Hospital Centenário. Jornal do Comércio, Recife, 1925 maio; 5 (1):3.

15. Hospital Centenário. Diário de Pernambuco, Recife, 1925 maio; 5 (1):3.

16. Fallecimentos. Jornal do Comércio, Recife, 1927 abr; 10 (1): 6.

17. Hospital Centenário. Diário de Pernambuco, Recife, 1925 maio; 25 (1):2.

18. Medeiros A. Cruzada Sanitária. Discursos. Recife (PE): Imprensa Oficial; 1924. 